\title{
Electric Technology in Wind Turbines from a Dialectic Perspective
}

\author{
Gonzalo Abad, Aritz Milikua, and Igor Baraia-Etxaburu
}

\begin{abstract}
Wind turbines have been used by many groups of humans for many centuries. Wind turbines have allowed groups of humans to perform many different tasks in the past (grinding grain, pumping water, etc.). However, only a century and a half ago, they began to be used to convert the energy captured from wind into electric energy. Moreover, only approximately twenty-five years ago, we started to introduce on a massive scale the energy generated from wind turbines into the electric networks of most developed countries in the world for regular consumption. According to 2017 statistics, approximately 12 percent of the electric energy consumed in the EU is produced by wind turbines. Despite the fact that wind turbines generally appear quite similar externally-i.e., a three-blade structure, a nacelle, a tower, etc.-if we carefully examine the electric technology used within them, we find quite a wide range of technologies for energy conversion, which is a key issue in wind turbine technology. Hence, this paper adopts a dialectic perspective towards analyzing and understanding why several electric technologies coexist in wind turbine technology. We explain the specific factors that have influenced different wind turbine manufacturers to adopt different electric technologies across the last twenty-five years. We show how their actions and the technological directions that have followed have been mutually codetermined, resulting in a technological evolution that has produced today's wind turbine variety.
\end{abstract}

Key words: wind turbine, electric technology, technology evolution, history of wind turbines, dialectic, codetermination, technique, science, technology

Gonzalo Abad, University Lecturer, Electronics and Computing Department, Mondragon Unibertsitatea, Faculty of Engineering, Loramendi, 4, 20500, Arrasate-Mondragón, Spain; telephone (34) 9437947 00. gabad@mondragon.edu.

Aritz Milikua, University Lecturer, Electronics and Computing Department, Mondragon Unibertsitatea, Faculty of Engineering, Loramendi, 4, 20500, Arrasate-Mondragón, Spain; telephone (34) 9437947 00. amilikua@mondragon.edu.

Igor Baraia-Etxaburu, University Lecturer, Electronics and Computing Department, Mondragon Unibertsitatea, Faculty of Engineering, Loramendi, 4, 20500, ArrasateMondragón, Spain; telephone (34) 9437947 00. ibaraia@mondragon.edu.

Open Access Article (CC-BY-NC 3.0) 


\section{Introduction}

Technology has been conceived and understood in many different ways by many different philosophers, thinkers, schools of philosophy, etc. There are many perspectives dealing with this idea, as in, for instance, recently published books by Robert Scharff and Val Dusek (2014) and Anthonie Meijers (2009), providing the views of many thinkers. Considering the countless number of publications, journals, books, philosophical contributions, etc., it is clear that technology is of vital importance to human beings when considered as a whole. Even in very specific contexts, regions or periods of time where historically it has been assumed that technology was absent, it is now being demonstrated that technological advances were more important than what was first thought (Camprubí 2014; Edgerton 2006). Regarding electric technology in wind turbines, there are numerous technical articles, books, patents, etc., written, including Erich Hau (2005), Bin Wu (2011), Gonzalo Abad et al. (2011), and Gonzalo Abad and Grzegorz Iwanski (2014). In addition, wind turbine technology is closely associated with a wider topic or philosophic idea: namely, 'energy.' There are also many philosophic works analyzing energy from authors such as Robert-Jan Geerts (2017), Sabine Roeser (2011), and Vaclav Smil (2007).

Hence, this paper adopts the ideas of technique, science, technology, and philosophy developed by the work of philosopher Gustavo Bueno, particularly Sciences and Categorical Closures (2013). We avoid the use of very complex or detailed definitions, instead using simple illustrative examples to defend the idea that technique is oriented towards obtaining an immediate practical use and does not (necessarily) include scientific knowledge (Alvargonzález 2013). Therefore, technique is developed by ancient potters, blacksmiths, stonecutters, architects, ship builders, etc. Alternately, sciences produce knowledges and are not necessarily oriented towards obtaining immediate practical use. As a result, we understand technology as techniques that may use or incorporate scientific knowledges. Finally, we understand philosophy as a 'second-degree' knowledge. Not because it is less, but because philosophy comes after techniques and sciences, which are 'first-degree' knowledge together with jurisprudence, politics, etc. Thus, philosophy analyzes, compares, discusses, goes further than, coordinates, etc., the knowledges generated by sciences, techniques, technologies, history, laws, etc.

With this view in mind, in the following paragraphs, we present a classification of the most representative ideas of technique. We then sort these ideas into eight different groups or models depending on their conception of technique, as 
has been proposed by Luis Carlos Martín Jiménez (2018). The criteria for distinguishing between the eight models of technique are three-fold: first, conceptions of technique that connect humans and technique in a positive or negative way; second, conceptions of technique that see, or do not see, connections between the sciences and technique; and finally, conceptions of technique that analyze technique in a very general or metaphysical way, in contrast to analyzing their specificity and/or variety. Here, it must be stressed that exhaustivity or completeness is almost impossible due to the high number of sources that historically have addressed this topic. Note that, because not all of the sources or models see techniques in connection with sciences for the production of technology, the term 'technique' will be adopted throughout this introductory section rather than 'technology.'

The first model Martín Jiménez calls the 'Negative view of technique.' This model is based on Aristotle's Nichomachean Ethics and other pre-Socratic philosophers. They do not conceive of technique as being connected to science. These philosophers say that technique developed by humans deviates us from reality or Nature. Therefore, this model degrades the idea of technique and thus degrades technicians as well. Technique is only understood as positive when we use it to imitate Nature: imitating, for instance, birdsongs with musical instruments. This view has been widely used and expanded upon by philosophers through the centuries.

The second model Martín Jiménez calls the 'degenerative view of technique.' This model is mostly associated with Christian theologians, especially from the Middle Ages (Bueno 2000). In this model, the technician is conceived of as a servant, because the only one who truly creates is God. Again, they do not see technique in connection with science, and in many aspects, this model is influenced by the first model. However, in this second model, the most important difference is the idea of God, who is the only creator (model 1 defends the concept of the "perpetuum mobile," stating: "nothing can emerge from nothing and nothing can be annihilated").

The third model Martín Jiménez calls the 'positive view of technique.' The main source for this positive view of technique is Francis Bacon (1964), but also other thinkers such as Paolo Rossi and Juan Luis Vives. This model dilutes the idea of science and says that technique is the truth. Therefore, this idea is not in contact with sciences. It says that technique gives us the power to control our natural surroundings. Bacon watched the impact of technique on society and claimed that, for instance, printing, the compass and gunpowder are technical inventions that dominate the world and are much more important than empires. 
The fourth model Martín Jiménez calls 'technical inventions are organic projections of human being.' The main philosophers supporting this idea of technique are Ernst Kapp (1972), Gilbert Simondon (1958), Teri McLuhan (1971), etc. In some way, they claim that technical developments are made strongly influenced by our unconscious. Thus, they say that human organs are projected in technique, i.e., that inventions are extensions of our body. For instance, ovens are extensions of the digestive system; electricity and electrical networks are an extended nervous system; states and governments are extensions of our own regulatory organs such as the brain and limbic system, etc. Note that these statements are metaphorical or metaphysical ideas of technique.

The fifth model Martín Jiménez calls 'technique presents its own life.' This model is supported by Jacques Ellul (1964), Herbert Marcuse (1998), and others. They say that human beings cannot control technical inventions. They state that technique is autonomous, presents its own life and tries to survive by seeking its own reproduction. It has to be highlighted that, from now on and in the following models, technique is seen in relation to science.

The sixth model Martín Jiménez calls 'an opportunity or event.' Martin Heidegger (1977) is probably the main philosopher supporting this thesis. It connects technique with his idea of Being and says that the Being is realized through technique. He says that the way of living of a human being is based on technique. Nonetheless, modern technique and sciences (Heidegger sees the advances in biotechnology and cybernetics) are going to hide the Being, or we simply are not going to be aware of it. The Being is going to be totally lost, and therefore, the human being is going to become just another object.

The seventh model Martín Jiménez calls 'technique is an orthopedic.' Within this model, we can distinguish the following philosophers: José Ortega y Gasset (1939), and Bernard Stiegler (1994). Basically, the thesis is that the human being is essentially a degenerated 'fetus' and an 'adoptive' creature. In some ways, the human being is weak, unable to do things autonomously, and depends on family and other people. Thus, in some ways, it is defended that desire comes from our subconscious dissatisfactions. Note that this model is different from model 4 , in which the human conception is confident and therefore is able to create technical inventions because it is capable of surpassing its own limits.

Finally, the eighth model Martín Jiménez calls 'dialectic.' Plato (Republic) is considered to be the original founder of this model, and the recently deceased Spanish philosopher Gustavo Bueno and his disciples follow the same statements. This model recognizes the importance of technique in relation to humans, adopt- 
ing a positive view of technique and remarking on the connection between techniques and sciences. Mainly, the idea is defended that the origins of the sciences were techniques (though obviously not at all of them). However, techniques and sciences are not the same (Bueno 2013). Hence, from dialectics between techniques and sciences, philosophy found its origin. The main thesis of the dialectic model is that techniques are essentially different and can be distinguished from each other. Nevertheless, they are strongly interconnected. Techniques can be specified, particularized and analyzed in detail. Thus, the dialectic model claims that the reason why technique is created and evolves is not at the level of generic mental conjectures or general metaphysical explanations, as these are merely simplifications or reductionisms of reality. Hence, this dialectic model accepts the previously defined models by stating that, in some specific or particular cases, the other models can provide appropriate analysis, but they are not sufficiently able to describe all contexts. Reality is much more complex and is given by the 'course of events.' In technique, every action that takes place is linked to operations with objects of corporeal subjects that are, in turn, related to other corporeal subjects, creating involving and co-determinant contexts. There is neither a generic nor metaphoric autonomous motor; only the specific and operatory exist. The typical illustrative example is a game of chess. Each move of one player determines the next move of the other player. Therefore, the situation after several moves has been codetermined by the specific move of each player, and the next situations will be codetermined by the subsequent specific moves. Consequently, the dialectic model proposes analyzing all of the specific techniques and understanding the details of the context that they determine. These specific determinant contexts are the only operative ones.

It should be highlighted that the dialectic model fits well with analysts of technology from different disciplines or contexts, such as sociologists, historians, anthropologists, and ethologists. These analysts are often attentive to a plurality of factors (as opposed to monists), to different actors and to the way in which social, technological, economic, and moral influences configure technological developments in specific contexts. These analysts include, for instance, Lewis Mumford (1934) or George Bassala (1989) and more contemporary analysts, such as David Pretel and Lino Camprubi (2018) and Geerts (2012). In addition, other approaches, such as Actor-Network Theory developed by Michel Callon (1990) and Bruno Latour (1987), among others, and Social Construction of Technology started by Wiebe E. Bijker, Thomas P. Hughes, and Trevor Pinch (1987), are also quite compatible with the dialectic model described above. 
Having described the most representative philosophic models of technique and having identified their connection to analysts from other disciplines as well, in subsequent sections we analyze the most important specific and codetermining events regarding electric technology development of wind turbines from a dialectic perspective (model eight).

\section{A Brief History of Wind Turbines}

\subsection{Introduction}

Today's wind turbine technology is rich and complex. It integrates the knowledges and advances of sciences and technologies from many different contexts. To be simple and at the same time accurate to the course of the historical events, we focus our analysis on the electric technology of wind turbines. This is the technology that enables us to convert the mechanical energy from the wind into electric energy that can be transmitted through the electric network and used by households and industry. Modern turbines generally use a three-blade design that can be seen in many parts of the world, though there are many other possible designs.

First, we will discuss the oldest events associated with wind turbine technology. Second, we briefly describe the main electricity inventions and their impact on wind turbine technology. Finally, we provide a specific and detailed analysis of the electric technology evolution in wind turbines over the last twenty-five years or so.

It is an impossible task to collect every single individual development and invention from all the parts of the world in relation to wind turbine evolution. Instead, this section is intended to provide a short guideline to some of the main advances as representative events. In Table 1, the most important events related to the wind turbine historical evolution are summarized. Going back almost two millennia, wind machines were used in Persia. They were created to offer small scale functionalities, quite far from how we use them currently. It is likely that, from these first inventions and thanks to contact between different civilizations, the idea was spread to different parts of the world. After that, different societies in many parts of the world developed different types of windmills for the same purposes, such as windmills in The Netherlands, in Spain, in Germany, in China and so on.

\subsection{Electricity Inventions and First Period of Wind Turbines for Electricity Production}

The first automatically operated windmill for electricity production was introduced around 1887-1888. James Blyth in the UK and Charles Brush in the United 
Table. 1. Most noteworthy events related to the wind turbine historical evolution. Main source: Tavner 2012.

\begin{tabular}{|c|c|c|}
\hline Date & Event & \\
\hline 7th century & $\begin{array}{l}\text { First practical windmills in Persia for grinding grain and pumping } \\
\text { water. }\end{array}$ & Old era \\
\hline $1887-1890$ & $\begin{array}{l}\text { First automatically operated windmills for electricity production } \\
\text { for battery charging: Charles Brush, USA, } 12 \mathrm{~kW} \text {, DC generator, } \\
\text { 144-blade wind turbine. James Blyth in UK and Poul la Cour in } \\
\text { Denmark built innovative designs of wind turbines with 10-kW DC } \\
\text { generators. }\end{array}$ & $\begin{array}{l}\text { Electricity } \\
\text { produciton } \\
\text { in DC }\end{array}$ \\
\hline 1910-1930 & $\begin{array}{l}\text { Mixture of American and Danish designs. 5- to } 35-\mathrm{kW} \text { designs are } \\
\text { built. Ups and downs due to the First World War, competition with } \\
\text { the diesel engine, etc. }\end{array}$ & \multirow{6}{*}{$\begin{array}{l}\text { Electricity } \\
\text { production } \\
\text { in AC }\end{array}$} \\
\hline 1931 & $\begin{array}{l}\text { In USSR, a modern three-blade WT is built }(100 \mathrm{~kW} \text { and } 100 \mathrm{~m} \text { in } \\
\text { height). It is connected to a } 6.3-\mathrm{kV} \text { distribution system. Clear signs of } \\
\text { aeronautical influence. }\end{array}$ & \\
\hline 1941 & $\begin{array}{l}\text { In the USA, the world's first megawatt size WT, connected to a local } \\
\text { electrical distribution system. } 1.25 \mathrm{MW}, \mathrm{D}=57 \mathrm{~m}, 40 \mathrm{~m} \text { in height. } 2 \\
\text { blades, geared drive, constant speed, downwind. First modern WT. }\end{array}$ & \\
\hline 1956-1966 & $\begin{array}{l}\text { In France, } 800 \mathrm{kVA}, 3 \text { blades, geared, pitch control, downwind. } \\
\text { Interesting design but no subsequent development (maybe because of } \\
\text { the French National decision to concentrate on nuclear power). }\end{array}$ & \\
\hline 1976-1980 & $\begin{array}{l}\text { Modern small-scale WT of } 1-10 \mathrm{~kW} \text {. In parallel, in Denmark, two } \\
\text { strong designs of } 200 \mathrm{~kW} \& 630 \mathrm{~kW}, 3 \text { blades, geared, one with pitch } \\
\text { control and one without, fixed speed. }\end{array}$ & \\
\hline 1980-1982 & $\begin{array}{l}\text { In USA, several 2-blade designs of } 200 \mathrm{~kW}, 2 \mathrm{MW} \text {, and } 2.5 \mathrm{MW} \text { with } \\
\text { pitch control are built, but they have unreliable results. }\end{array}$ & \\
\hline 1983-1988 & $\begin{array}{l}\text { In Germany a 3-MW, 2-blade design is made with a fully rated } \\
\text { cycloconverter, but it is unreliable. } \\
\text { In the UK, a 1-MW, three-blade, fixed speed design. Simple and } \\
\text { reliable but lacks a market. }\end{array}$ & \multirow{2}{*}{$\begin{array}{l}\text { Massive } \\
\text { installation } \\
\text { of wind } \\
\text { turbines for } \\
\text { electricity } \\
\text { production }\end{array}$} \\
\hline 1995-2018 & $\begin{array}{l}\text { 1- to 8-MW High-Power Commercial Wind Turbines. Pitch control, } \\
\text { direct/geared drive, with grid code compliance, onshore/offshore, } \\
\text { PM/DFIG/SCIG/WRSG, etc. }\end{array}$ & \\
\hline
\end{tabular}

States were able to convert energy coming from the wind into electric energy by automatically charging batteries. Brush used a 12-kilo-Watt $(\mathrm{kW})$ Direct Current (DC) generator, and the windmill design was made of 144 blades. Some months before, Blyth had used a 10-kW DC generator as well for charging batteries. A few years later, Poul la Cour in Denmark designed innovative wind turbines as well with 10-kW DC generators (Hau 2005). 


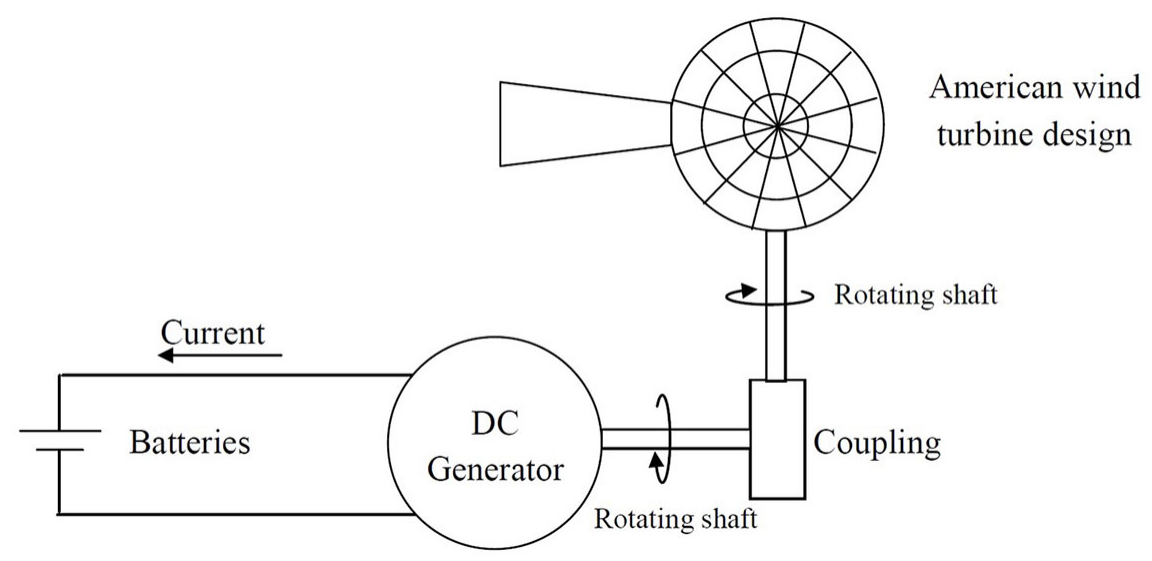

Figure 1. Electric configuration of first automatically operated wind turbines.

The two main electrical innovations used by these inventors were the DC machine (a DC machine can operate both as a motor or as a generator) and the batteries, as illustrated in Figure 1. These two specific electrical inventions had also been successfully introduced in other application contexts a few years earlier. For example, in 1879, Werner von Siemens developed the first electrically powered locomotive in Berlin for the transportation of passengers. In 1880, Siemens built the first electric elevator. In 1882, Thomas Edison developed the New York City DC distribution system. In 1888, Isaac Peral in Spain developed the first submarine with DC electric propulsion and batteries. In 1897, the London Electric Cab Company inaugurated a service of electric vehicles powered by batteries. These previously successful uses of electrical power and storage, well known to people of the era, created the determinant contexts that led Blyth and Brush to transfer electric technology to wind turbines.

If we pay attention to the electric inventions themselves, taking the DC motor first, the first patented DC motor was built by Thomas Davenport in 1837 . He was neither a scientist nor engineer as we understand them currently, but rather a blacksmith. After buying an electromagnet based on the designs of Joseph Henry, Davenport forged a better iron core and redid the wiring, using silk from his wife's wedding gown, thereby successfully assembling his rotating DC motor. In addition, Michael Faraday performed several experiments inspired by the experiments of others, including Hans Orsted, obtaining in 1821, probably for the first time, electromagnetic rotation. In 1827, Faraday also demonstrated induction by means of basic electromagnetic devices. For batteries, in 1800, Alessandro Volta 
invented the voltaic battery (called a "voltaic pile" at the time) consisting of zinc and copper plates immersed in diluted sulfuric acid. He based his inventions on the experiments of others, such as Galvani's 'animal electricity' discoveries. These extremely important and meritorious experimental discoveries were not based on advanced scientific knowledge as we understand it today. They were more founded on technical skills, manipulation and combination of elements, manual assembly capacities, intuition and imagination, rather than being based on mathematical, scientific or theoretical formulations. Most of the theorems or analytical laws explaining these discoveries were described later. For instance, Ohm's law wasn't formulated until 1827. Then, Ampere in 1831 and Lenz in 1834 described their theoretical formulations of the electromagnetic field. Then, much later in 1861, Maxwell integrated all these experimental proofs and theoretical formulations, creating a theoretical global framework with its 20 differential equations of electromagnetism. Regarding batteries, after Volta's experiments, in 1859, Gaston Planté invented the first lead-acid battery, incorporating more chemistrybased scientific knowledge. We note in passing that, currently, in all universities for scientists and engineers, this framework has become a standard for teaching and explaining electromagnetism and electricity in general, using the laws and theorems enunciated after the experimental discoveries (Hayt and Buck 2019), (Crowell 2007) and (Fraile-Mora and Fraile-Ardanuy 2015).

There seems to be, however, a general ignorance of how the discoveries were made and how they propagate through a variety of determinant contexts involving inventors and theoreticians. In fact, broadly speaking, we might say that today's technicians and training professionals are taught electronics and magnetism in a similar manner to Faraday or Volta, through technical and tradescraft training first, and only gaining and using theoretical knowledge later. Most engineers understand electricity and magnetism, incorporating subsequently developed laws, i.e., Lenz, Ampere, Ohm, Weber and so on, while more advanced scientists and engineers will make use of Maxwell's laws and equations. In each of these instances the more 'technic'-based inventions were carried out first and that the scientific knowledge was incorporated by others later.

In the last half of the nineteenth century the Alternating Current (AC) machine was developed in a similar way to the DC motor, by sequential innovations or discoveries based on manually assembled experiments. Without attempting to be exhaustive we should highlight that, in 1885, Ferraris and Tesla experimentally developed the rotating magnetic field by poly-phase AC stator windings. Then, in 1887-1888, Haselwander built the first three-phase AC synchronous generator 
with salient poles. During the years 1889-1891, Dobrovolsky developed the cage induction AC motor. In 1891, Tesla developed the poly-phase AC alternator, and Dobrovolsky developed the first three-phase $\mathrm{AC}$ generator and $\mathrm{AC}$ transformer, thereby creating the first complete AC three-phase system (Fraile-Mora 2016).

In the following years, companies offering $\mathrm{AC}$ systems competed with companies offering DC systems (The War of the Currents). Finally, AC systems prevailed for several reasons, an important one being the absence of a DC transformer in DC systems. AC transformers enabled the creation of interconnected efficient networks in cities that were progressively incorporating electrifications into their group of houses. Thus, thanks mainly to AC transformers, AC systems displaced previously developed DC systems, thereby establishing AC systems as dominant (Hernández-Callejo 2019). Since AC systems become dominant, AC wind turbines started to be developed. For that purpose, AC generators and transformers were incorporated to wind turbine technology, as shown in Figure 2, enabling it to be connected to AC network systems, spreading and progressively growing in many countries.

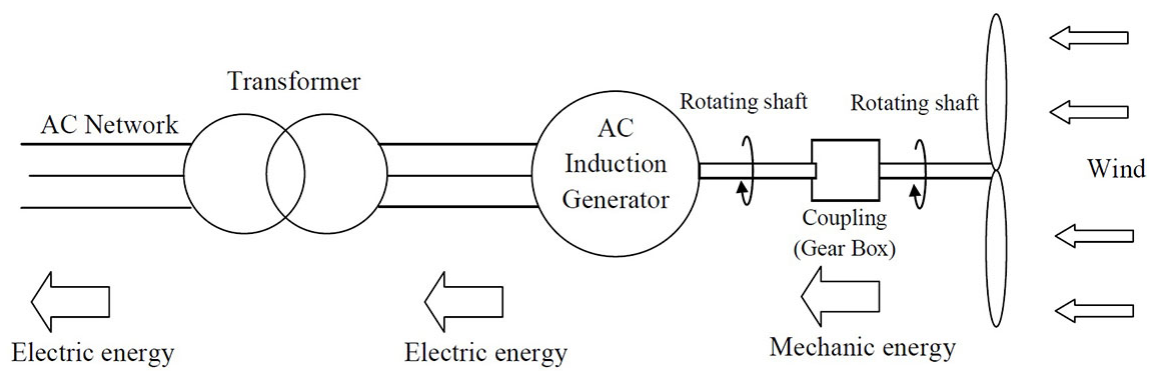

Figure 2. Electric configuration of an AC generator-based wind turbine.

The inventors of the AC generators and transformers did not conceive of their prototypes through the use of mathematical or physical knowledge. Although they knew the theoretical laws describing the electromagnetic phenomena (Ohm Lenz, Ampere and so on), the mathematical tools were not developed until years later. The synchronous AC machine analytical model in a synchronous rotating reference frame was developed by Park in 1929; the AC induction motor model in a stationary reference frame was defined by Stanley in 1938; or all the mathematical tools and analyses published by Edith Clarke in 1943 (Abad 2016). We should note that these mathematical tools and electrophysical theories were developed to explain and analyze existing AC motors mathematically and to develop the corre- 
sponding control algorithms. Today, they are standard and indispensable tools for understanding AC motors, though Ferraris, Tesla, and Dobrovolsky, together with other inventors involved in AC systems, developed their inventions with a more rudimentary scientific knowledge than many people believe today.

After Blyth, Brush, and la Cour's pioneering developments using DC generators and batteries, $\mathrm{AC}$ generators and transformers were used by engineers to connect wind turbines to AC networks at the beginning of the twentieth century. As a result, in the following years, and especially between 1910 and 1930, the turbine's physical morphology, a mixture of American and Danish designs was built, with a range of powers between 5-35 kW and always with AC generators when connected to the networks. During this period, wind turbine developments suffered ups and downs due to the First World War and competition with the diesel engine, among other factors, as described in Table 1.

From 1990 until today, modern wind turbines evolved very quickly compared with any other period in their history. Wind turbine presence for energy generation has been spread nearly everywhere, and the number of wind turbines installed all around the world has been increasing constantly. In the last twenty-five years, a significant number of different wind turbine topologies have arisen, not only from their electric technology point of view but also from their mechanical and structural topologies. Depending on the country, location, time of installation and other factors, we can find wind turbines from approximately 1 Mega-Watt (MW) of power up to $8 \mathrm{MW}$, which is currently the highest-power commercial wind turbine. The three-blade structure is the dominant configuration at this power range. The following section attempts to analyze in detail the electric technology evolution of wind turbines over the last twenty-five years.

\subsection{Historical Evolution of Electric Technology in Wind Turbines over the Last Twenty-Five Years: Massive Installation of Wind Turbines}

In the previous subsection, we described how, in the nineteenth century, the first operated wind turbine for electricity production was a result of the parallel evolution of wind turbines to do different tasks (other than electricity production) on the one hand and the advances in the field of electricity on the other. More specifically, inventions of DC electric generators and batteries at first, but then later the invention of $\mathrm{AC}$ generators and transformers for connecting to electric distribution systems and many other secondary elements (switches, fuses, breakers, etc.). By the early 1990s, the dominant electric technology in wind turbines was the fixed speed wind turbine based on the 'squirrel cage'" induction generator (fixed-speed 
SCIG). It is the first AC generator topology employed in the early years of the twentieth century (same as Figure 2) and the one that was dominantly used until the 1990s when connecting a wind turbine to an AC network.

As schematically represented in Figure 2, in wind turbines, the three-blade system that rotates and captures the mechanical energy from the wind is mechanically coupled to the generator, which converts that mechanical energy into electric energy. Because the rotation speeds necessary to maintain suitable electrical current generation within the induction generator is significantly higher than the rotation speeds (safely) achievable by the turbine's blades a gearbox is introduced between the two. One basic characteristic of these turbines is that the rotating speed of the blades is fixed (a small variation actually occurs but can be neglected in practice) and determined by the frequency of the AC grid's voltage. This means that the rotational speed does not change depending on the wind speed.

This particular organization of electric technologies has proven to be both robust and reliable and has dominated the market for many years. Reliability and robustness were the two main factors that had to be proved by wind turbine manufacturers (Vestas, Gamesa, Nordex, Acciona, Enercon, Mitsubishi, etc.), or more specifically, for technology makers working in these companies during the late 1980s and early 1990s to grid suppliers. Many groups of people exhibited reticence to regularly connect wind turbines to the grid; grid system operators (GSO) were not clear whether it could be problematic, technically speaking, for grid stability and safety; engineers working at other conventional generation systems perceived wind turbines as a technical and market threat; others said that it would cause problems for the animals and ecosystems where the turbines were going to be installed; while still others said that the wind turbines would cause psychological or physiological illness in people living in surrounding areas. Nonetheless, wind turbine manufacturers proved that fixed-speed wind turbines based on the squirrel cage induction generator could successfully address these reluctances.

Once the wind turbines had been added in considerable number to the electric grid of some pioneering countries and were able to show their capacity to generate energy at a reasonable cost without causing excessive problems, engineers were able to move past questions of reliability into technologies that could maximize the efficiency of the turbines. Technology makers of wind turbine manufacturers had known for many years that, if they could control the rotation speed of the blades of the wind turbine, adapting this rotation speed to the wind speed at any given time, they could maximize the amount of energy the turbines would produce. From the application of basic hydrodynamic knowledge developed in the eighteenth century 
by Bernoulli, Venturini and others physicists to the blades of the wind turbines (García, Morales, and Escalante 2004), they knew that, at each wind speed that faces one specific wind turbine, it is possible to find a maximum peak of the generated power as illustrated in Figure 3. Exploiting this technological fact, the efficiency of wind turbines would be increased significantly, now being able to work at the maximum power extraction point from the wind at any time. Nonetheless, this was not possible with fixed-speed turbine technology. Engineers introduced power electronic devices, such as diodes and controlled semiconductors to make the variable-speed wind turbine possible. This power electronics technology was evolving at the same time, obtaining successful results in other contexts, such as in ship propulsion, industry applications and railway traction (Abad 2016).
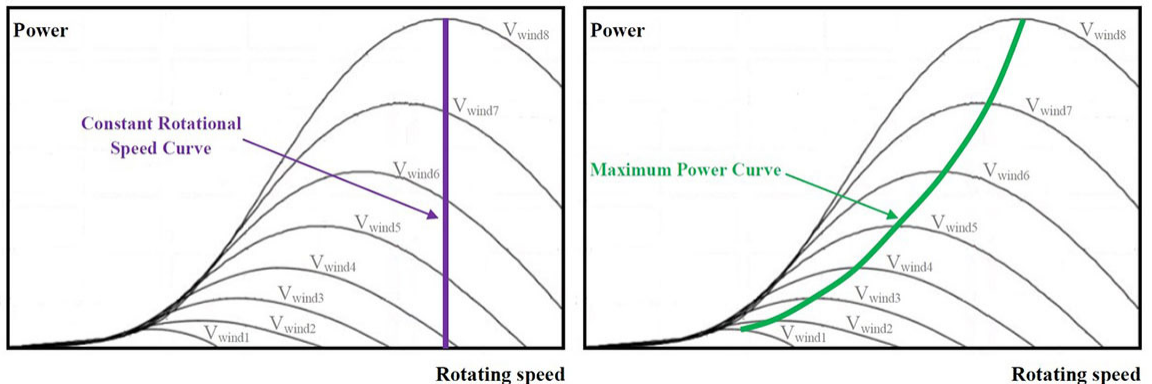

Figure 3. Efficiency Improvement: Power generation capacity of wind turbines as a function of wind speed $\left(V_{\text {wind }}\right)$, at fixed rotating speed on the left and variable rotating speed of the blades on the right (Abad et al. 2011).

The main historical events in the production of different semiconductor technologies can be summarized as follows (Abad 2016): In 1882, J. Jasmin discovered the phenomenon of semiconductance and proposed its use in AC rectifying, which is a basic application area of semiconductors; in 1892, Leo Arons developed the first mercury-arc vacuum valve; in 1897, Leo Graetz developed the three-phase diode bridge rectifier (one more basic application area of semiconductors), and in 1902, Peter Cooper Hewitt patented the mercury-arc rectifier; in 1906, Greenleaf Whittier Pickard proposed the silicon valve; and finally in 1948, the nowadays so much used bipolar transistor was invented by John Bardeen, Walter Houser Brattain, and William Bradford Shockley. By the middle of the twentieth century semiconductor-based electronics started to be applied to a variety of applications and purposes. Bardeen, Brattain and Shockley developed this achievement under the umbrella of a big research organization: Bell Telephone Laboratories. At the 
end of World War II, Bell Laboratories employed approximately 11,000 people, of whom approximately one-third were scientists and engineers, approximately onethird were technical aides, and approximately one-third were clerical and support personnel (Lojek 2007). This shows that, by this time, technology advances were starting to be made within the framework of organized groups of people (companies, research organizations and universities, basically). These engineers merge a variety of multidisciplinary knowledge: "pure" scientists (for instance, physicians and mathematicians), engineers, technicians, organizers and so on. The (disputed) model of the lone inventor from past centuries became increasingly rare, though individual, very skilled technicians were obviously present in these organizations.

After these advances in semiconductors, in 1952, General Electric manufactured the first germanium diodes (Abad 2016), another basic semiconductor. Then, in 1954, Texas Instruments produced a silicon transistor with high commercial acceptance, and in 1956, John Moll, Morry Tanenbaum, James Goldey, and Nick Holonyak invented the thyristor. Later, once the market and functional stability of these devices had been well-established, and demand for better performance started to increase, in 1983, General Electric invented the semiconductor called insulated-gate bipolar transistor (IGBT). The IGBT is currently used in all modern wind turbines and dominate many other applications as well, including railway traction, ship propulsion and a huge variety of industry applications (Abad 2016). These semiconductors are the basic elements that, once assembled, enable engineers and technology makers to develop complex and sophisticated power electronic converters that allow electricity to be converted from DC to AC and vice versa. However, these power electronic converters must be appropriately controlled to do what the engineers want to do in an efficient and reliable manner. To this end, the technology of microprocessors and control algorithms evolved hand in hand. Since Intel introduced the first 4-bit and 8-bit microprocessors in 1972 (based on low-power semiconductor technology from Bardeen et al.), many other advances have been made in microprocessor developments and electronic devices providing computational calculation capacity (Abad 2016). These variants of microprocessors are ready to run the control algorithms that were being developed, oriented towards power electronics applications. The control algorithms are in charge of accurately control variables such as; the speed of a train, the effort made by an elevator, the energy captured from the wind by a wind turbine, etc. Almost all of these already well-established control algorithms in industry are evolutions and improvements of two basic fundamental control algorithm families: 'vector control algorithms,' pioneered by K. Hasse and F. Blaschke in 1968-1972, 
and 'hysteresis-based control algorithms,' developed by Allan B. Plunkett, Akira Nabae, Isao Takahashi, Hirofumi Akagi, and others between 1979 and 1981 (Abad 2016).

Advances made in these basic technologies - power electronics semiconductors, microprocessors and the corresponding control algorithms-led technology makers to incorporate them successfully in different contexts. This, in turn, resulted in quantifiable improvements in the performances of established devices, such as trains, ships, many home appliances (cooking, lighting, washing machines), industry applications (machine tools, mining, etc.) and so on. This determinant context led wind turbine manufacturers to also incorporate these technologies into wind turbines. In a competitive market context among technology makers, the first manufacturer achieving a quantifiable product improvement would improve their market position considerably. Therefore, knowing theoretically, as shown in Figure 3, that they could extract more power from the wind through a variablespeed design, technology makers of wind turbines incorporated power electronic converters, microprocessors and sophisticated control algorithms to develop the variable-speed wind turbines as illustrated in Figure 4.

We feel that the previous paragraph has been a rather pessimistic narration of the perspective position of wind turbine manufacturers. It is only fair to point out, therefore, that the authors have, from their experience, observed a widespread positive attitude among wind turbine manufacturers. In general, they view the introduction of power electronics in wind turbines as a great challenge and opportunity to improve the products that they offer to society as a whole. In fact, technology makers in the 1990s, of and for wind turbines from companies such as Vestas, Ingeteam, ABB, Siemens, Mitsubishi, Gamesa, Nordex, and many others, were without doubt pioneers of enormous importance in introducing power electronics in new application areas, wind turbines in this case. This kind of feat could never have arisen from pessimism; it was achieved with a tremendous dose of enthusiasm, in the same way that today's technology makers generally face their challenges.

In the early 1990s, engineers introduced the reduced-variable-speed wind turbine shown in Figure 5b, based on the more complex wound rotor induction generator (WRIG). With this technology, it was possible to obtain a short variation of the rotating speed of the blades, thereby capturing more energy from the wind, resulting in more efficient power generation compared to the previous fixed-speed ones. This was an intermediate step between the fixed-speed and the fully variable- 


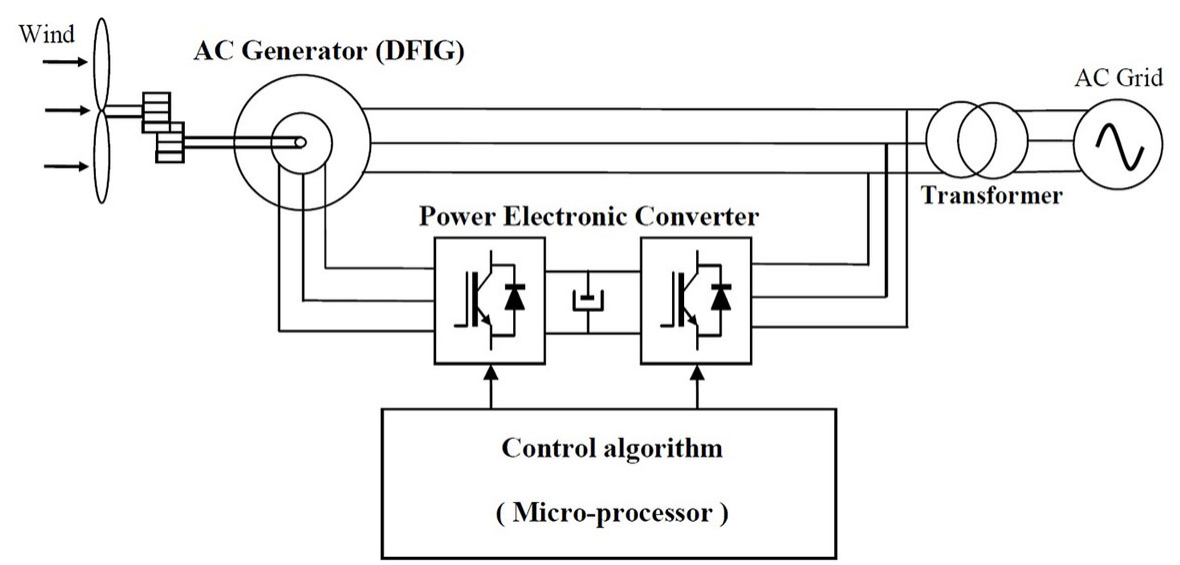

Figure 4. Variable speed wind turbine, based on the Doubly Fed Induction Generator electric technology (variable-speed DFIG). It incorporates power electronic converter technology for supplying the rotor of the generator and microprocessor technology for controlling the entire wind turbine.

speed wind turbines. This technology was adopted because manufacturers at that time were not one hundred percent sure of their knowledge in power electronics.

Among the disadvantages of this new 'non fixed speed' wind turbine technology includes a generator concept design more complex, heavy, and expensive; and the introduction of power electronic devices also increased the complexity and cost of the resulting overall technology. Because the captured energy from the wind was greater than that from fixed-speed turbines, wind turbine manufacturers soon proved that this topology was more cost-effective in the long term and sufficiently reliable.

Still in the middle of the 1990s more or less, the variable-speed wind turbine was developed based on the Doubly Fed Induction Generator (variable-speed DFIG). Thanks to this topology (Figure 5c, same as Figure 4), the electric technology employed made it possible to obtain a range of rotation speeds from the blades, capturing the maximum available energy at the current wind speed. The new technology was more complex and more expensive, however, in a short time, wind turbine manufacturers also proved that the technology was reliable and able to offer increased economic benefits. These changes and improvements in the electric technology of wind turbines were encouraged by determinant contexts, the most important of which are highlighted in red in Figure 6. 

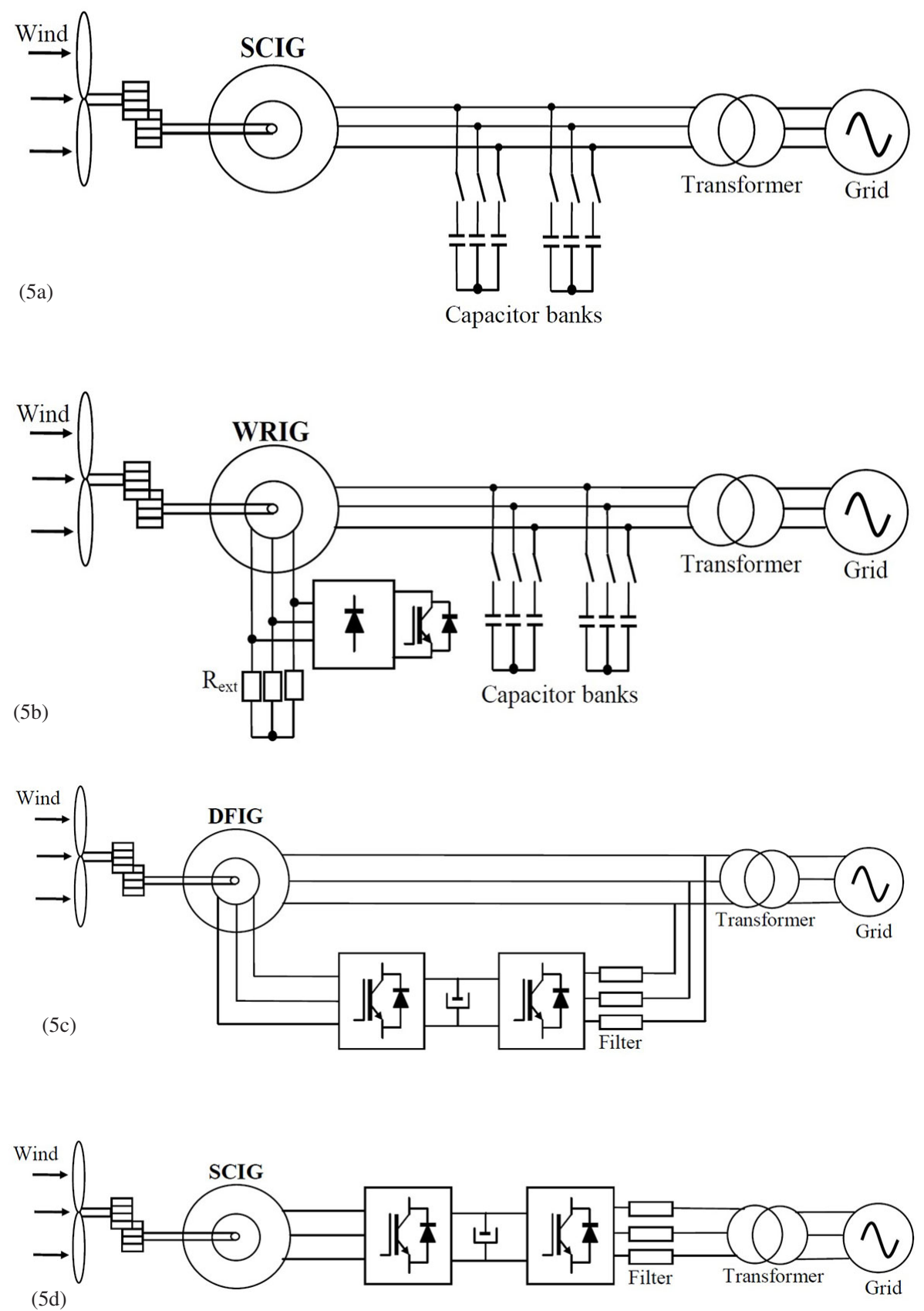

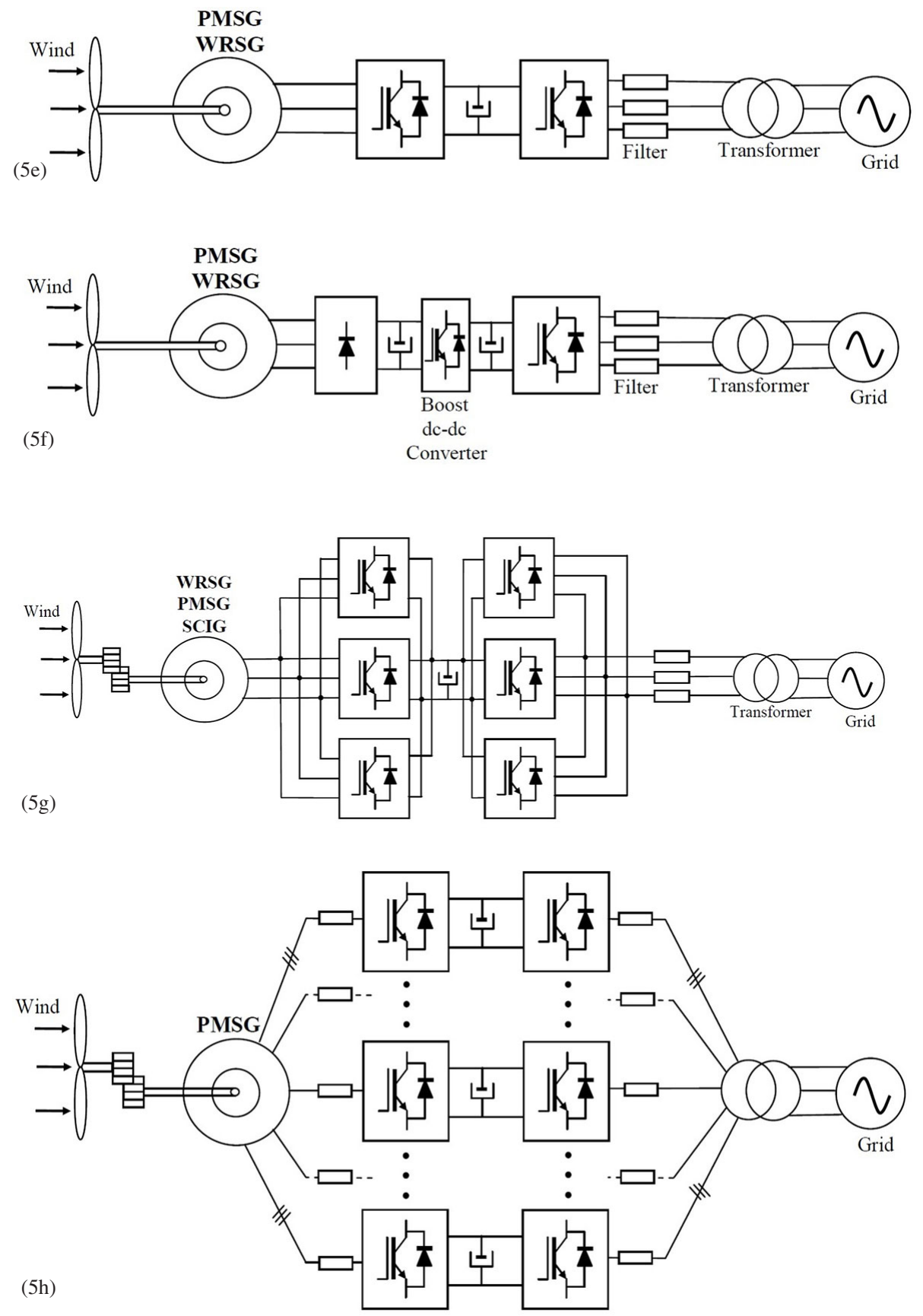

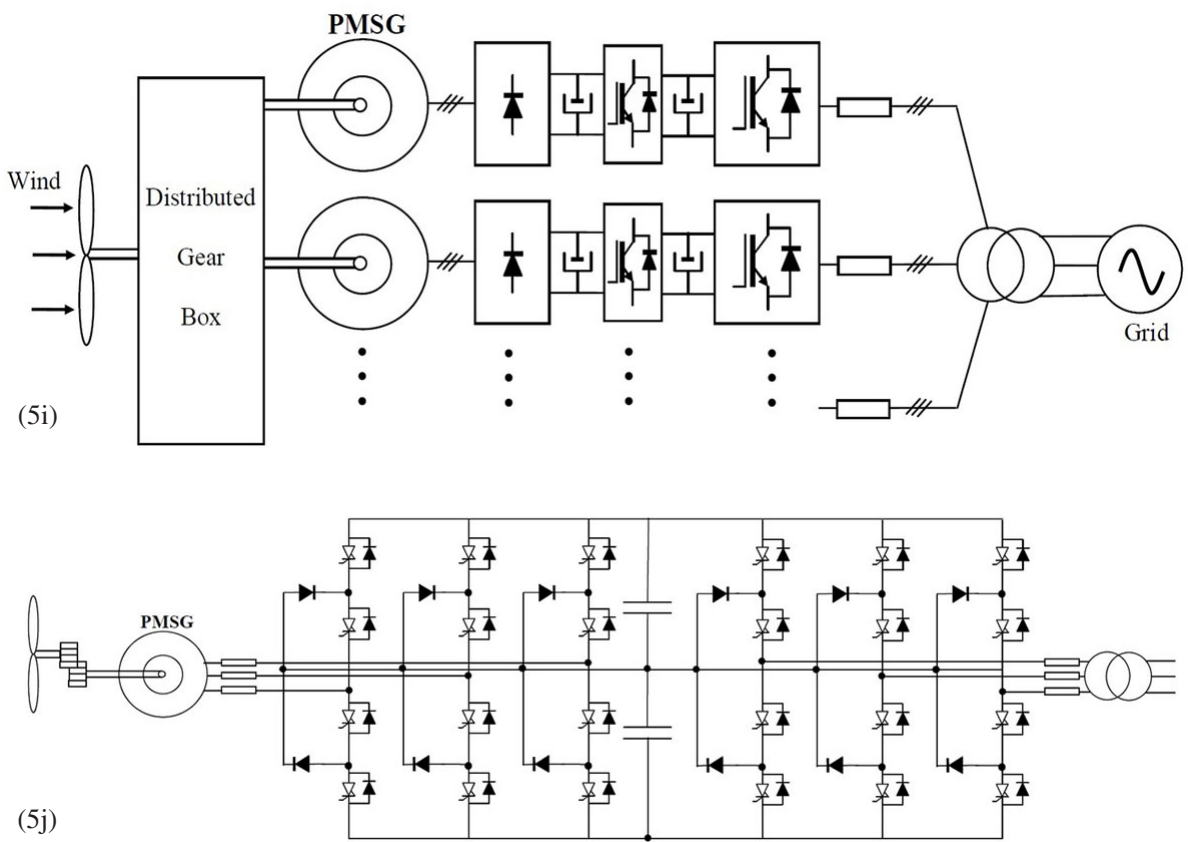

Figure 5. Dominant electric topologies in wind turbines. (a) fixed-speed SCIG, (b) Reduced-variablespeed WRIG, (c) variable-speed DFIG, (d) variable-speed full converter SCIG, (e) variable-speed direct drive full converter PMSG and WRSG, (f) variable-speed full converter with boost converter, (g) variable-speed full converter with parallelization, (h) variable-speed full converter with multiwinding PMSG, (i) variable-speed full converter with distributed gearbox, (j) variable-speed with medium voltage full converter. * microprocessor and control algorithms accompanying the power electronic converters have been omitted from the pictures for simplicity.

In the beginning, reliability was the major concern. It was compulsory to prove that wind turbine technology was able to be installed without causing other problems. Once this premise had been fulfilled by wind turbine manufacturers, soon other requirements not so important in the past started to gain more priority such as efficiency (understood in the sense of being able to extract more energy from the wind).

Afterwards, the third major concern distinguished in Figure 6 was to improve the cost, volume, weight, and adaptability to different turbine characteristics (power level, voltage level, dimensions of the nacelle and so on). The physical restrictions of the electronic elements that are inside a wind turbine strongly determine the turbine's essential structure or morphology, as illustrated in Figure 7. 


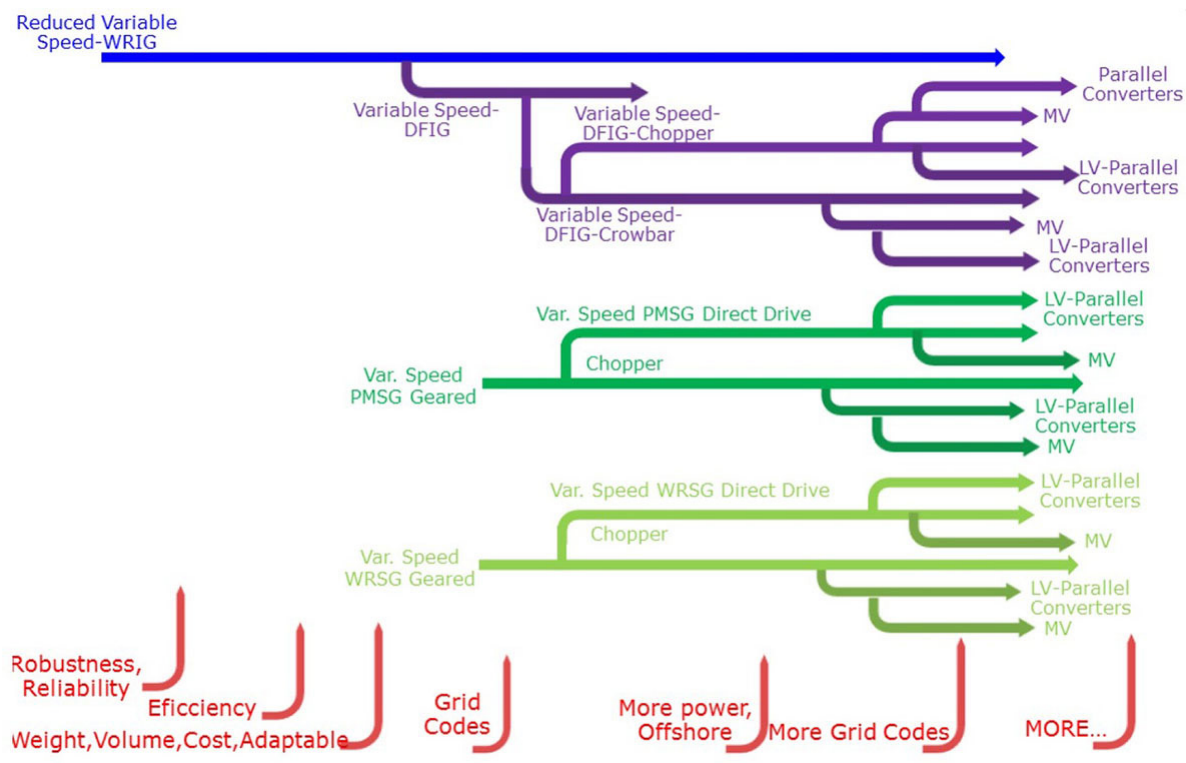

Figure 6. Evolution of electric wind turbine technology over the last twenty-five years approximately (left: early 1990s; right: 2018).

These issues, which at the beginning were not so critical, soon became more and more important. The changing priorities slowly shaped the desired characteristics of the electric and electronic elements mounted in wind turbines. Thus, reduction of cost, weight, and volume became requirements of market competitiveness, and forced technology makers to be truly ingenuous in, for instance, new designs of electric generators and converters. For example, optimizing the shapes, structures and locations of the different elements (compacted coil heads in generators, reduced bus bars in converters, etc.). These challenges were met successfully thanks to finely honed technical skills combined with advanced scientific knowledge. Advanced thermal analysis and new sophisticated methods for heat evacuation (based on air or deionized water) began to be applied widely to design more compact and optimized electric generators and power electronic converters. Computer-based simulation tools that helped to perform a huge number of numerical computations also started to be widely used by technology makers. These simulation tools enabled technology makers to create advanced designs of generators and power electronic converters both more quickly and with greater sophistication. 


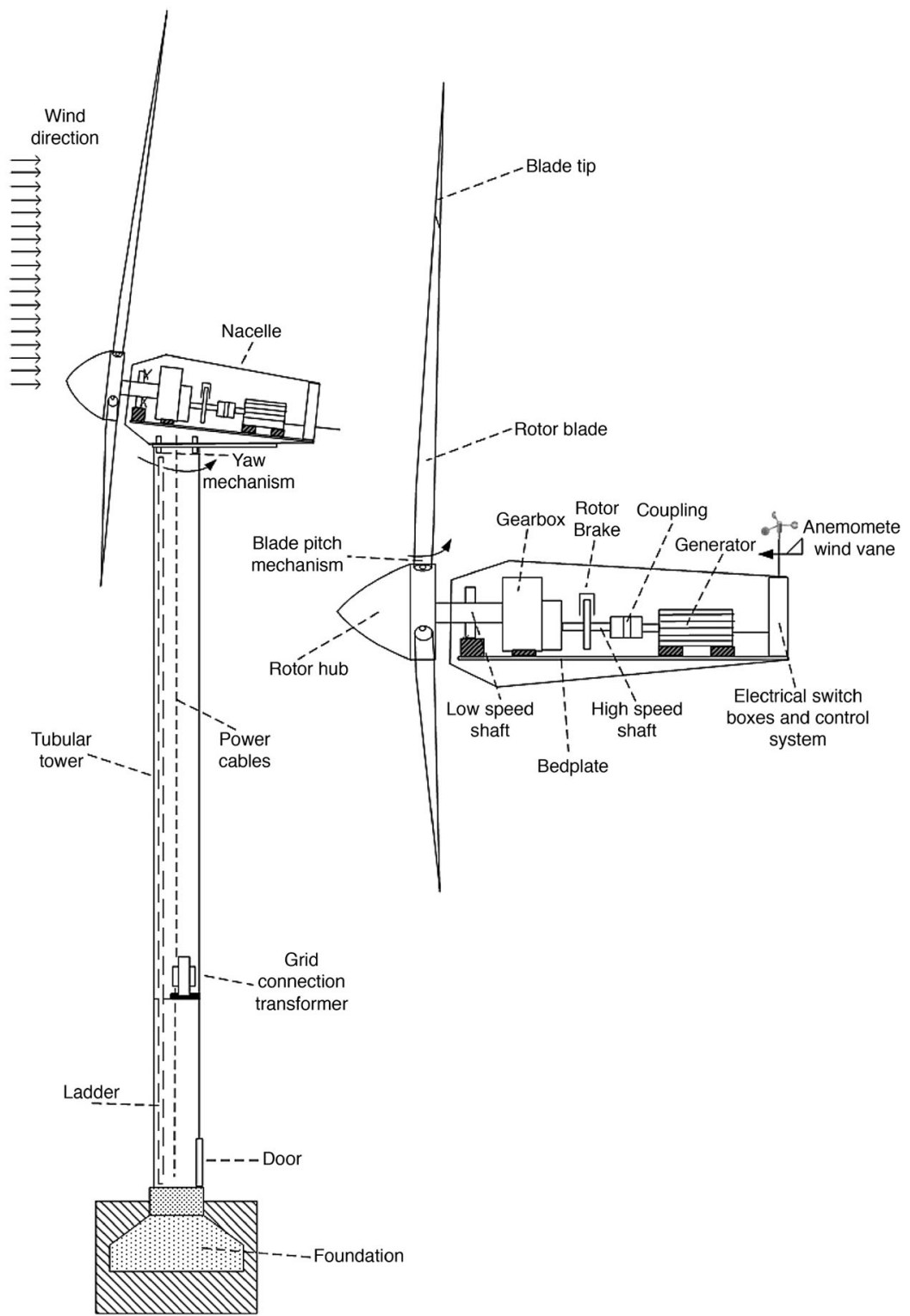

Figure 7. Weight, Volume, and Cost Reduction: Picture showing the main electronic elements that are inside a modern wind turbine. It gives an idea of the physical restrictions of the elements within: volume, forms, weight, and modularity to be simply replaced if failed. 
These new changes introduced in the technology never completely displaced the others but instead cohabitate with them both within individual turbines, and between them as well. Different wind turbine technologies are installed in different locations and by different manufacturers, depending on many factors. As a consequence of this codeterminant scenario, the variable speed DFIG wind turbine concept, Figure 5c, experienced a significant growth in market share, becoming the dominant technology offered by manufacturers until the middle of the 2000 s.

Nevertheless, the growth of another new factor in the middle of the 2000ths had a great influence on wind turbine technology (Abad et al. 2011): grid code compliances (fourth red arrow in Figure 6). In countries where the penetration of wind generation was becoming more and more significant, the countries simultaneously became more and more dependent on wind generation. Therefore, these countries started to standardize the characteristics and regulate the behavior of wind turbines, creating more and more restrictive (or deterministic) grid codes or rules. In particular, when grid faults occur (quick voltage variations in the grid voltage due to undesired and unavoidable contingencies such as: lightning in storms, falling of trees on distribution lines, isolator failures, etc.), grid system operators started to demand that wind turbines, first not disconnect from the grid and, second, contribute to the fault clearance. Originally, wind turbines were allowed to simply disconnect from the grid and therefore protect themselves from the fault contingency, as damage to the electronic components could be significant. However, in the context of a high penetration of wind generation, these disconnections became prohibited by grid codes created by network operators, in order to be able to maintain grid coherency and avoid large blackouts.

As illustrative examples, we can describe two significant events that occurred in two leading European countries (in terms of installed capacity of wind generation) in the middle of the 2000s. In Germany, on the fourth of November 2006, during a normal and programed opening of a new $400 \mathrm{kV}$ line, a sequence of unexpected and uncontrolled events produced a propagation of faults (reflected in frequency deviations) across almost all of Europe, as illustrated in Figure 8 (a). All of the complementary and auxiliary generation services were activated in Europe, preventing a large-scale blackout. Similarly, one year later in Spain, as illustrated in Figure 8 (b), a severe fault in Mudarra also propagated through a large portion of the country (Domínguez et al. 2008). There was one main reason for these two events (and some others that occurred elsewhere): the electric networks of the countries were not fully prepared for such a large capacity of wind generation that, 
at that time, was allowed to be simply disconnected from the grid under minimum problematic events.

This was quite a clear codetermining context, created by the technologies themselves (wind turbines' performances during unexpected faults and electricity network infrastructures) and the operating actors involved in it. Once the networks were operating, the wind turbines were operating as well. Users needed the energy generated by wind turbines, and there was a large industry dependent on the jobs proportioned by the wind turbine manufacturers. The economies of countries, in turn, were dependent on the incomes of these companies, with the only possible option being to adapt wind turbines to address this challenge, based on knowledge and technology, while taking care not to destroy the industry by demanding unreachable performances.

To address this new demand and challenge, manufacturers of DFIG-based wind turbines needed to add a protective element based on power electronics and resistances (specially designed to consume high amounts of energy in short periods of time). This new element would be installed either at the rotor (called the "crowbar") or at the DC bus (called the "DC chopper"), adding complexity, volume, and cost to the wind turbine. The reasons to adopt one protective element or the other (crowbar or chopper) for companies were numerous: follow a path with less technological jump, differentiate from the competitors, avoid patents, etc.

Accordingly, previously installed and operating technological elements, i.e., wind turbines in electric networks, created unexpected challenges that were again addressed by combining new technological devices (protective crowbars and choppers) with advanced scientific knowledge. One noteworthy mathematical technique that was incorporated into the wind turbine context was the sequence
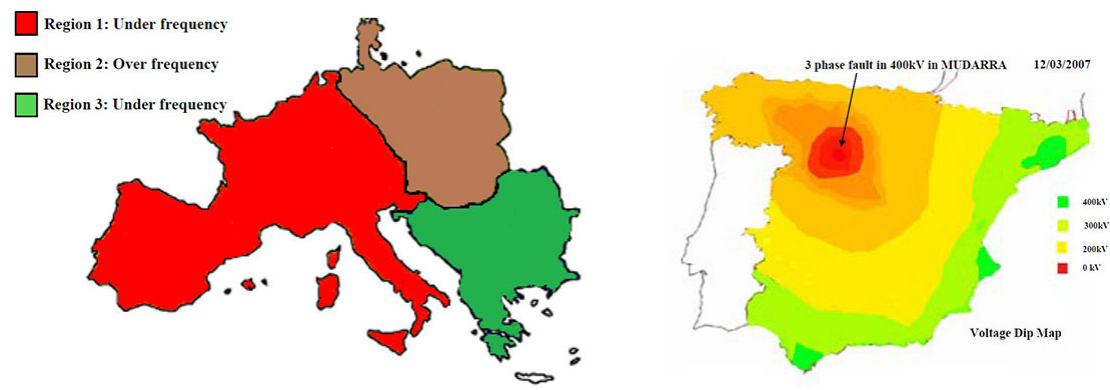

Figure 8. Grid Code Requirements: (left) German case in 2006: propagation of uncontrolled events after a programmed opening of a line, (right) Spanish case in 2007: propagation through a large extension of Spain from a severe fault occurring in Mudarra. 
decomposition analysis developed by Fortescue at the beginning of the twentieth century. As demanded by the grid codes of different countries, it was necessary to understand how asymmetrical faults affect wind turbine behavior and, as a consequence, be able to design effective protective elements (crowbars and choppers) and make wind turbines operate as required during the faults. Thus, more complex mathematical models of wind turbines were developed, integrating sequence decomposition, thereby making it possible to know precisely what happened at the faults, to develop associated control algorithms, and finally, to develop far more sophisticated wind turbines with capacities and performances that would have been unimaginable fifteen years earlier.

Similarly, the already existing mathematical methods of analysis for AC networks also experienced an important boost. These methods (that found their origin at the beginning of the twentieth century in mathematicians such as Steinmetz, Heaviside and Clarke) were being developed and improved continuously while integrating numerical computation methods provided by computers' capacities (Hernández-Callejo 2019). These mathematical methods of analysis of AC networks integrated wind turbines as another common actor to be necessarily considered.

In the meantime, variable speed wind turbines with full-scale power electronic converters (Figures 5d and 5e) and based on different generator topologies (Squirrel Cage Induction Generator-SCIG, Wound Rotor Synchronous GeneratorWRSG, and Permanent Magnet Synchronous Generator-PMSG) that were installed in lower numbers during these years started to gain force by wind turbine manufacturers. While the full-scale converter had been considered in the past to have disadvantages (being bulky, expensive and complex), once the grid code demands were restrictive, this became, in principle, an advantage for meeting the more restrictive grid code requirements emerging in comparison with a DFIG wind turbine. This fact resulted in more manufacturers adopting the full-scale converterbased wind turbines, thereby becoming clear competitors to DFIG-based wind turbines. Consequently, between the years 2006 and 2009, approximately 75 percent of the new most-modern installed wind turbines were based on the DFIG concept, and the rest were based on full-scale converter wind turbines (Sakki 2009). This approximate relation of 1 to 4 has been progressively narrowing since then. Continuous technological improvements enforced the variable speed wind turbine based on the direct drive concept (Figures 5e and 5f) but, after 2007-2009, gained an increasing presence among manufacturers. In the following years, manufacturers continued to develop newer wind turbines based on their specialized technologies and creating improved models meeting the needs mainly of (red vectors of 


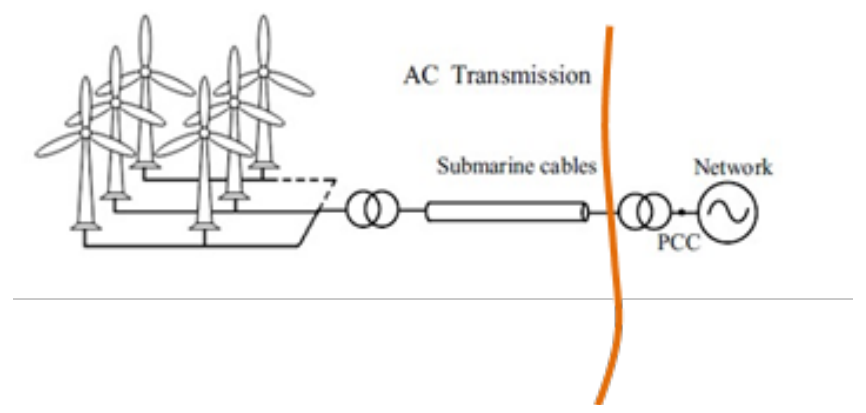

Figure 9. Offshore Wind Farms: Schematic representation of an offshore wind farm.

Figure 6): reliability, efficiency, adaptability, dimensions, cost, and grid code compliance. However, from approximately 2010, a new tendency began to influence wind turbine technological evolution: the offshore location of wind farms (fifth red arrow in Figure 6), as schematically represented in Figure 9. The main reasons that influenced wind turbine operators to go offshore were to find locations with better wind conditions and to find locations far from continuous human presence.

By this time, factors such as increasing the power of wind turbines and their reliability to reduce costs associated with maintenance became very important, since their offshore location significantly increased the costs of installation and maintenance. Therefore, efforts were made by manufacturers to adapt wind turbine technologies to increase their rated power, and topologies such as Figures $5 \mathrm{~g}$ to $5 \mathrm{j}$ started to gain force. One tendency was to parallelize existing power electronics converters, such as those in Figures $5 \mathrm{~g}$ and $5 \mathrm{~h}$. Another trend was to increase the complexity of the mechanical gearbox and use the same electric technology as in Figure 5i; another was to go for newer versions of high-power electronic converters as in Figure 5j.

The challenge to install offshore wind farms led technology makers to introduce complex modulation algorithms (multilevel or interleaving modulations) to increase power generations. Additionally, optimized electromagnetic elements (zero blocking transformers or interphase transformers for converter parallelization) were designed using advanced electromagnetism knowledge and specialized computer-based software packages. Similarly, to improve and predict the reliability of the electronic technology developed, already existing statistical analysis methods were adapted and applied to wind turbines. More globally advanced electrophysical models of other elements present at the wind farm-such as transformers, substations, and submarine and subterranean cables-were also starting to be developed extensively. General mathematical tools, such as curve-fitting methods, 
Foster network methods for variable impedance representation, etc., were adapted and introduced by technology makers to this wind farm context. Through the introduction of these technologies, engineers were able to produce more global and accurate mathematical models which could analyze interactions between all the elements present at a wind farm, under very specific and particular operating conditions and avoid future unexpected problems. Note that most of this scientific knowledge is still continuously being incorporated currently, while many offshore wind farms are already installed and operating. Thus, for instance, consider submarine cables, which have been around for many years; technology makers (not necessarily cable manufacturers) are continuously studying and analyzing them via more and more sophisticated scientific tools, trying to improve their performances and characteristics. The same occurs with many other elements, such as batteries, capacitors, diodes, fuses, and so on.

Therefore, all these described facts have significantly increased the number of electric technology branches or concepts in wind turbines, as seen at today's date in Figure 6. The diversification of wind turbine technology is a result of several courses of events that have affected wind turbine manufacturers, who then produced different technologies as their contexts required. This resulted in wind turbines evolving in different directions while meeting the different requirements at each historical moment.

In conclusion, each technology has found its own niche or market, while more determining contexts today are inevitably leading technology makers of wind turbines to incorporate new improvements and new technological trends. Finally, it has to be emphasized that the electric technology evolution of wind turbines described in this subsection is inevitably a reduced version of reality as it actually occurred. That said, even if events have been simplified, the most important and dominant tendencies are presented here. In addition, all of the scientific knowledge that this technology has incorporated to improve the designs, as described in previous paragraphs, is still being used and continuously improving, evolving hand in hand with the technology of wind turbines itself.

\section{Conclusions}

Having analyzed the evolution of electric technology in wind turbines, we conclude first by providing some quantitative tendencies in wind energy generation from the last two decades. According to the statistics reported by the main associations of wind power industries, such as Wind Europe or Global Wind Energy Council (GWEC), with regard to the size of wind turbines, there is a clear tendency to increase the 
power (and therefore the dimensions) of commercial wind turbines (GWEC 2018). The largest wind turbine today is of $8 \mathrm{MW}$ and $165 \mathrm{~m}$ in blade diameter. This indicator parallels two other indicators which also show growth: the installed average power of wind turbines, and installed average power of wind farms. This means that, in the last two decades, the trend has always been to install larger wind turbines and larger wind farms. These correlated tendencies are also connected to another tendency in the last two decades: the dropping economic cost of producing wind energy due to the economies of scale. In other words, the tendency to develop larger wind turbines and larger wind farms generates a reduction in the costs of the wind energy production. Finally, these tendencies are also correlated with another tendency of the last two decades: the increase in cumulative wind power installed around the world. In 2017, approximately 500 gigawatts (GW) of wind power energy is installed all around the world (GWEC 2018). This is approximately $160 \mathrm{GW}$ in the EU, which is approximately 12 percent of the total power installed and consumed in EU (123 million EU houses). These tendencies can also be accompanied by some other numbers that show the importance gained by wind turbine technology as reported by the Global Wind Energy Council: in 2016, wind power avoided over 637 million tons of $\mathrm{CO}_{2}$ emissions globally, thanks to 341,320 wind turbines spinning around the world. We also note that a modern wind turbine is a very complex element, consisting of approximately 8,000 different parts and that the industry surrounding wind turbines created, in 2016, approximately 1,150,000 jobs worldwide (GWEC 2018).

This global importance and global trend is, as shown in the article, the consequence of a technological evolution precipitated by technology makers of wind turbine manufacturers, influenced by many different factors. Thus, as shown in section 2, this technological evolution can be perfectly understood and explained by applying the 'dialectic method.' To this end, in section 2, the authors found and analyzed in detail the most determinant contexts that have led wind turbine makers, in contact with a variety of technological developments themselves, along with a plurality of different actors (grid operators, scientists, groups of consumers, etc.), to develop this variety of technologies. At the same time, it has also been illustrated how, with every single development, a constant pattern has occurred throughout technologies' evolution: the particular innovative development first comes based on a 'more technical mode.' After the developments are materialized or implemented, many scientific contributions (math, physics, chemistry, etc.) enrich and reinforce the 'more technical' development. On every occasion, each single action, development or contribution has been made by technology makers, operating with clear and concise objectives. 


\section{Note}

1. The rotor of the generator incorporates a cage of copper or aluminum, very similar in shape to a squirrel cage.

\section{References}

Abad, Gonzalo. 2016. Power Electronics and Electric Drives for Traction Applications. Chichester. Wiley. https://doi.org/10.1002/9781118954454

Abad, Gonzalo, and Grzegorz Iwanski. 2014. "Properties and Control of a Doubly Fed Induction Machine.” In Power Electronics for Renewable Energy Systems, Transportation and Industrial Applications, ed. Haitham Abu-Rub, Mariusz Malinowski, and Kaman Al-Haddad, 270-318. Chichester: John Wiley \& Sons. https://doi.org/10.1002/9781118755525.ch10

Abad, Gonzalo, Jesús López, Miguel Rodríguez, Luis Marroyo, and Grzegorz Iwanski. 2011. Doubly Fed Induction Machine: Modeling and Control for Wind Energy Generation. New Jersey: John Wiley \& Sons. https://doi.org/10.1002/9781118104965

Alvargonzález, David. 2013. “Ciencias humanas y ciencias divinas.” Daimon Journal of Philosophy 58: 109-24.

Aristotle. 1985. Nichomachean Ethics, trans. Terence Irwin. Indianapolis: Hackett.

Bacon, Francis. 1964. Thoughts and Conclusions on the Interpretation of Nature as a Science Productive of Works, trans. Benjamin Farrington. In The Philosophy of Francis Bacon. Liverpool: Liverpool University Press.

Bassala, George. 1989. The Evolution of Technology. Cambridge: Cambridge University Press.

Bijker, Wiebe E., Thomas P. Hughes, and Trevor Pinch. 1987. The Social Construction of Technological Systems: New Directions in the Sociology and History of Technology. Cambridge, MA: MIT Press.

Bueno, Gustavo. 2000. Televisión, apariencia y realidad. Barcelona: Gedisa.

Bueno, Gustavo. 2013. Sciences and categorical closures. Oviedo: Pentalfa.

Callon, Michel. 1990. "Techno-economic Networks and Irreversibility." The Sociological Review 38(1): 132-61.

https://doi.org/10.1111/j.1467-954X.1990.tb03351.x

Camprubí, Lino. 2014. Engineers and the Making of the Francoist Regim. Cambridge, MA: MIT Press. https://doi.org/10.7551/mitpress/9780262027175.001.0001

Crowell, Bejamin. 2007. Electricity and Magnetism. Fullerton: Light and Matter.

Domínguez, Tomás, Miguel de la Torre, Guillermo Juberías, Eduardo Prieto, Rosalía Rivas, and Eduardo Ruiz. 2008. "Renewable Energy Supervision and Real Time 
Production Control in Spain." International Conference on Renewable Energies and Power Quality 1(6): 377-82. https://doi.org/10.24084/repqj06.302

Edgerton, David. 2006. The Shock of the Old. London: Profile Books Ltd.

Ellul, Jacques. 1964. The Technological Society. Toronto: Random House of Canada Limited.

Fraile-Mora, Jesús. 2016. Máquinas eléctricas. Madrid: Garceta.

Fraile-Mora, Jesús, and Jesús Fraile-Ardanuy. 2015. Electromagnetismo. Teoría y problemas. Madrid: Garceta.

García, Jorge, Armando Morales, and Eduardo José Escalante. 2004. Mecánica de Fluidos: antecedentes y actualidad. Mérida: Ediciones de la Universidad Autónoma de Yucatán.

Geerts, Robert-Jan. 2012. "Self-Practices and the Experiential Gap: An Analysis of Moral Behavior around Electricity Consumption." Techné: Research in Philosophy and Technology 16(2): 94-104. https://doi.org/10.5840/techne201216210

Geerts, Robert-Jan. 2017. "Towards a Qualitative Assessment of Energy Practices: Illich and Borgmann on Energy in Society." Philosophy \& Technology 30(4): 521-40. https://doi.org/10.1007/s13347-017-0262-6

Global Wind Energy Council (GWEC). 2018. Global Wind Energy Council. https:// gwec.net/. Accessed January 20, 2018.

Hau, Erich. 2005. Wind Turbines: Fundamentals, Technologies, Applications, Economics. Berlin: Springer.

Hayt, Wiliam H., and John A. Buck. 2019. Engineering Electromagnetics. New York: McGraw-Hill.

Heidegger, Martin. 1977. The Question Concerning Technology, trans. Willian Lovitt. New York: Harper and Row.

Hernández-Callejo, Luis. 2019. Microredes eléctricas: Integración de generación renovable distribuida, almacenamiento distribuido e inteligencia. Madrid: Garceta.

Kapp, Ernst. 1972. Grundlinien einer Philosophie der Technik. Hamburg: Meiner.

Latour, Bruno. 1987. Science in Action: How to Follow Scientists and Engineers through Society. Milton Keynes, UK: Open University Press.

Lojek, Bo. 2007, History of Semiconductor Engineering. Berlin: Springer.

Marcuse, Herbert. 1998. Technology, War and Fascism. London: Routledge.

Martín Jiménez, Luis Carlos. 2018. Filosofía de la técnica y de la tecnología. Oviedo: Pentalfa.

McLuhan, Teri. C. 1971. Touch the Earth. New York: Simon \& Schuster.

Meijers, Anthonie, ed. 2009. Philosophy of Technology and Engineering Sciences. North Holland: Elsevier.

Mumford, Lewis. 1934. Technics and Civilization. Chicago: University of Chicago Press. 
Ortega y Gasset, José. 1939. Meditación de la técnica: Ensimismamiento y alteración. Madrid: Espasa Calpe.

Plato. 1992. Republic, VIII, trans. George. M. A. Grube and C. D. C. Reeve. Indianapolis: Hackett.

Pretel, David, and Lino Camprubí. 2018. Technology and Globalisation: Networks of Experts in World History. Cham: Palgrave Macmillan. https://doi.org/10.1007/978-3-319-75450-5

Roeser, Sabine. 2011. "Nuclear Energy, Risk, and Emotions." Philosophy \& Technology 24(2): 197-201. https://doi.org/10.1007/s13347-011-0027-6

Sakki, Raimo. 2009. “Technology Trends of Wind Power Generators.” Nordic Conference, R8 Power Chapters Leadership Workshop and IAS Technical Seminar on Wind Power Technologies, Stockholm.

Scharff, Robert C., and Val Dusek. 2014. Philosophy of Technology. Chichester: Wiley-Blackwell.

Simondon, Gilbert. 1958. Du Mode d'Existence des Objets Techniques. Paris: Aubier.

Smil, Vaclav. 2007. Energy in Nature and Society: General Energetics of Complex Systems. Cambridge, MA: MIT Press.

Stiegler, Bernard. 1994. Technics and Time. Stanford, CA: Stanford University Press.

Tavner, Peter. 2012. Offshore Wind Turbines: Reliability, Availability and Maintenance. London: IET. Digital Library. https://doi.org/10.1049/PBRN013E

Wu, Bin. 2011. Power Conversion and Control of Wind Energy Systems. Hoboken, N.J.: John Wiley \& Sons. https://doi.org/10.1002/9781118029008 